\title{
The Role of Brand and Fan Personalities in Building Fan-Brand Relationships
}

\author{
Mohamed Mosaad, Faculty of Commerce, Cairo University, Egypt \\ Ehab AbouAish, Faculty of Commerce, Cairo University, Egypt \\ Mohamed H. Elsharnouby, Faculty of Commerce, Cairo University, Egypt \& Faculty of Business and Economics, Badr \\ University in Cairo, Egypt
}

\begin{abstract}
Football fans are consumers with special relationships with their favourite teams. Consumer-brand relationship is unique and ultimate in a football context. However, the absence of these relationships is mainly due to a lack of communication and interaction. This research aims to investigate the impact of brand personality and fan personality on fan-brand relationships. Mixed methods were conducted that employed in-depth personal interviews with football professionals and fans to gain better insights regarding consumer-brand relationships and to develop a conceptual framework and research hypotheses. Then, a quantitative phase has been followed to test these hypotheses. Four hundred seventy-one valid questionnaires were collected through a non-probability convenience sampling technique from Egyptian football fans. The findings have shown that brand personality and fan personality have a positive impact on interdependence, commitment, partner quality, self-connection, nostalgic attachment, intimacy as consumer-brand relationship dimensions in the football context.
\end{abstract}

\section{KEYWORDS}

Brand Personality, Egypt, Fan Personality, Fan-Brand Relationship, Football, Qualitative Data Analysis, Quantitative Data Analysis, Sports Industry

\section{INTRODUCTION}

The consumer and brand relationships have increasingly got the attention of academics and practitioners, particularly in the marketing field (e.g. Elsharnouby, et al., 2021). Companies work hard and pay wealth to identify how consumers relate to their brands and why some brands are preferred and even loved. Consumers feel emotions, bear sacrifice and commitment, engage with brands, and develop loyalty (Cirillo and Cantone 2015). Sport- entertainment is currently considered to be an industry and one of the most important factors in the growth of the national economy in many developed countries (Asadollahi et al. 2015). The popularity of sports events has made it possible to reach wide audiences. Branding and customer relationship management (CRM) together with the commercialization and professionalization of the sports industry are key elements in the achievement of sports teams and their brands (Karjaluoto et al. 2016).

Consumer (e.g. fan) and brand (e.g. club) relationship in the football sector is one of the most critical and unique research areas since the relationship between football fans and their favorite teams is special and long-lasting. The key issues of the sports brand are fan attraction, developing loyal relationships with its fans, inspiring them to become more attached to the brand. Therefore, many sports clubs act as commercial brands and obtain marketing practices and competencies to develop a 
well-established relationship with their fans (Cirillo and Cantone 2015). Sports executives increasingly see their clubs as brands to be managed. Therefore, their goal is to create a strong brand that can affect the behavior of external target groups, irrespective of sports success. According to Keller (2001), there are four steps to build a strong brand. 1) To ensure that the brand is identified with its consumers and that the brand is associated with a particular product class or customer need. 2) To firmly establish the meaning of the brand in the minds of customers by strategically linking several tangible and intangible brand associations. 3) To obtain the precise customer response to this brand identity and brand meaning. 4) To convert brand responses to establish consumer brand relationship.

The brand personality as a part of the brand image affects the behavior of target groups (Schade et al., 2014). In other words, brand personality can help sports managers to establish a brand image, which strongly influences the fans' behaviors. Therefore, it is important to examine the brand personality in the sports industry. Well established brand personality can serve as an important source of emotional bonding between consumer and brand, a helpful tool to develop a lasting long term relationship with consumers (Ahmad and Thyagaraj 2014), and a strategic tool for differentiating and creating a consumer-brand relationship (Guèvremont and Grohmann 2013). The successful consumer-brand relationship depends not only on relationship marketing practices but also on consumer personality. In othe words, the consumer-brand relationship is developed through consumers' and brands' interactions (Fournier 1998).

The sports industry is an important individual, organizational, and national economic sector and a major contributor to economic activity and the creation of wealth (Goldman and Johns 2009). Major sports events can deliver significant benefits- both tangible impacts such as additional visitor expenditure and intangible effects such as national pride, the profile of sports, and participation (Deloitte 2008). The expenditure of global corporate sponsorship in 2007 was estimated at \$ 37.7 billion and about $66 \%$ of all sponsorship expenditures were allocated to sporting events (Lee and Cho, 2009). According to the IEG Sponsorship Report (2018), North American companies increased spending on sporting events to $\$ 16.2$ billion in 2017, up about 3.6\% from \$ 15.7 billion in 2016 (IEG, 2018). The sports industry has become one of the most important sectors for many countries worldwide because it produces and promotes numerous products and services, affects many consumers and supporters and even affects the national security. Although the importance of fan-brand relations in sport industry, few studies have investigated this concept in the sports context, especially in the developing countries. Therefore, this research aims to investigate the impact of the personality of both parties (fan and brand) on fan-brand relationship in the sports context in order to fill the gap in the literature.

Based on reviewing the literature, there is a lack of academic research related to sport brand relationships (e.g. Kunkel and Biscaia 2020). Specifically, there is a lack in exploring and examining the impact of different aspects such as brand personality and consumer personality on the relationship between football fans and their favorite teams. Since there was much attention on consumer-brand relationships, it is valuable to highlight and examine these types of relationships in different contexts such as sports. The relationship between sports fans and their favorite teams in a sports context is unique, important, and special. Therefore, it is considered as a special context in which the subject can be explored more because of the deep connection of emotions and the strong relationship stability between fan and their teams (Cirillo and Cantone 2015). Besides, it is worth noting that a little attention had investigated this relationship in the sports context in developing countries. Therefore, the current study fills these gaps by answering the following research questions; 1) does team personality play a role in the relationship between football fans and their favorite teams? 2) Do fan personality traits play a role in the relationship between football fans and their favorite teams? Thus, the current study aims to investigate the impact of team personality and fan personality on each of the fan-brand relationship dimensions (brand interdependence, brand commitment, partner quality, self-connection, nostalgic attachment, intimacy. The current research uses the word "brand" to refer to a sports club. 


\section{BRAND PERSONALITY}

The concept of brand personality is widely used by marketers as a differentiation tool and to build a competitive advantage (Ahmad and Thyagaraj 2014). Advertisers and marketers were the first to coincide with the term "brand personality" long before the academics studied and accepted the concept (Azoulay and Kapferer 2003). The term of brand personality was first mentioned by Ogilvy (1955) when he was giving a lecture to the American Associate of Advertising Agencies. Since Martineau (1958) has introduced the concept of store image and store personality, researchers have started to investigate more into the concept of brand personality (Hartman and Spiro 2005).

\subsection{Brand Personality Definition And Importance}

Similar to people, products have their unique personalities that they can make them orbreaktheminthemarketplace (Ogilvy, 1983). Several brands are thought to have personalities that are not determined solely by the actual physical attributes of the product but by a variety of other factors such as advertising, the firm's image, the image of users, the origin of the product, etc. (Yoon 2004). Although the concept of brand personality is familiar and accepted by both practitioners and academics, researchers do not agree on what brand personality is (Aaker and Fournier 1995). For example, Kapferer (1997) believes that brand personality is one of the elements of brand identity that together with physique, culture, relationship, reflection and self-image represent the ultimate vision and goal of a brand. Giving the brand a spokesman or a figurehead is the easiest way to create brand personality. Gordon (1996) suggests that brand personality is a metaphor for the emotional relationship that exists between a brand and consumer, while it is the emotional response of the consumer to a brand that embodies attributes. Brand personality is also a set of human characteristics linked to a brand (Aaker, 1997) that is followed by the current research because of its acceptance.

Traditionally, brand strategies focussed on the functional or utilitarian benefits of products and services. However, increased competition in industries over recent decades has caused more problems in the differentiation of brands, based solely on functional features. Products or services become more functionally similar to each other and easy to copy based on their attributes (Yoon, 2004). Therefore, researchers and branding practitioners started to use brand personality as a helpful tool to differentiate brands from its competitors, develop a lasting long term consumer-brand relationship (Ahmad and Thyagaraj 2014), develop emotional features of a brand, and increase the personal benefits of a brand to consumers (Aaker and Fournier 1995).

\subsection{Dimensions Of Brand Personality}

While the considerable investigation has been done in personality psychology to conceptualize the human personality, to identify the "Big Five" dimensions, and to explore the meaning of each dimension, in consumer behavior on the brand personality, there has been no parallel investigation (e.g. Aaker 1997; Ghantous, 2016; Seimiene, 2012). Inspired by the Big Five model, Aaker (1997) suggested that brand personality dimensions could be defined by extending human characteristic dimensions to those of brands. From the 309 personality traits generated through an assembly of the list of traits used in psychology and marketing studies to describe and measure the human personality, Aaker (1997) conducted several studies using different brands from various product and service categories. As a result, the dimensions were labeled as competence, sincerity, excitement, sophistication, and ruggedness. Although the scale of Aaker (1997) is widely accepted and used by researchers, some studies criticized the scale's generalizability and validity. For example, Geuens et al. (2009) summarized these criticisms as follow: The first criticism refers to the loose definition of brand personality which leads to construct validity problem. The second criticism refers to the nongeneralizability of the factor structure. The third criticism refers to the non-cross culture validity. Ross (2008) and Schade et al. (2014) believe that Aaker's scale cannot be applied to sports brands. Researchers, therefore, began to apply that scale to different categories of products and services, 
leading to various scales of brand personality such as Geuens et al.' (2009) brand personality scale (Responsible, active, aggressive, simple, and emotionally attractive), and Bosnjak et al.' (2007) scale (drive, conscientiousness, emotion, and superficiality). However, in professional sports clubs, this scale was not developed and validated. Therefore, Tsiotsou (2012) developed the first valid and reliable scale (competitiveness, prestige, morality, authenticity, and credibility). Later, Mitsis and Leckie (2016) validated and extended Tsiotsou's (2012) scale.

\subsection{Brand Personality In The Sports Industry}

In recent years, there has been an increasing amount of literature on the personality of sports brands (i.e. organizations, teams, and events) (e.g. Kim et al. 2019; Schade et al. 2014; Tsiotsou, 2012). People usually refer to professional sports teams as human beings. For example, teams are commonly described as being 'successful, 'ambitious, 'or 'uncompromising' (Tsiotsou 2012). Such associations can help professional teams in attracting more fans and sponsors (Blank and Baumgartner 2018). The symbolic, experiential, and hedonic characteristics of sports brands make the study of their personalities appealing and imperative. Furthermore, it has been important for team managers and marketing practitioners to understand how consumers perceive the personality of sports brands (Tsiotsou 2012).

Therefore, researchers started to investigate more in this field of research. For example, Karjaluoto et al. (2016) examined the direct and indirect effects of the personality of a sports team, the identification of sports fans with the team, and the impact of the long relationship between fans and a team on their loyalty to the team. As a result, they found out that: First, the identification with a team mediates the effects of brand personality on attitudinal loyalty and behavioral loyalty; second, brand personality is a stronger driver of identification among new fans; and third, brand personality has a stronger influence on attitudinal and behavioral loyalty among new fans. Furthermore, Aiken et al. (2013) investigated the dimensions of brand personality associated with professional sports teams and the dimensions of the personality of the cities they call home. They found out that similar personality traits are attributed to both the team and their city.

\section{FAN PERSONALITY}

Understanding consumer behavior is the ultimate goal for marketers because it helps managers to better determine the appropriate target segment and better design and deliver the ultimate value for consumers (Bray 2008). In consumer behavior, consumers are influenced by a multitude of environmental, cultural, personal, and psychological factors in searching, buying, using, and disposing of products and services. One psychological element documented in the literature is the personality of the consumer (Solomon 2011). Personality is an abstract concept and therefore presenting an accurate description of personality is quite difficult. Scientists also frequently describe personality in the context of the subject or field being analyzed, which is why there are many descriptions of personality concepts (Seimiene 2012). The difficulty in defining this concept because the personality is something difficult to describe in one sentence due to its vast and dynamic (Udo-Imeh et al. 2015). Mayer (2007) compared definitions of personality from four different textbooks on personality. Although the definitions of personality from these textbooks were worded differently, its central idea remains the same. These definitions share in common the view that (a) personality is a psychological system, (b) composed of a group of parts (c) that interact, (d) and develop, and (e) that impact a person's behavioral expression (Mayer, 2007). Therefore, investigating consumer personality in the context of sport is needed to provide better insights into how the personality of football fans can shape their relations and behaviors toward their favorite teams. 


\section{FAN-BRAND RELATIONSHIP}

Fan as a consumer relationship with brands has become a topic of growing interest and attention in the marketing literature (e.g. Bryan et al. 2006). Blackston's (1993) book chapter beyond brand personality: Building brand Relationships, followed by Fajer and Schouten's (1995) article Breakdown and Dissolution of person-brand relationships, and finally Fournier's (1998) paper on consumers and their Brands: Developing relationship theory in consumer research are considered as the pioneers in the field of consumer-brand relationship (Fetscherin and Heinrich, 2015).

\subsection{Consumer-Brand Relationship Theory}

Fournier (1998) developed the brand relationship theory. This theory was developed based on the idea that consumers humanize objects and think of brands as if they have human personalities. Brands cannot act, feel or think themselves, but can live and evolve through the practices of their managers (Loureiro 2013). Based on the interpersonal interaction metaphor, Fournier (1998) developed a brand relationship quality model that was the starting point for a huge amount of research in consumerbrand relationships (Loureiro 2013). The brand relationship quality model consists of six facets: Love and passion, self-connection, brand partner quality, intimacy, commitment, and interdependence (Fournier, 1998). Considerable studies have been carried out in brand management to conceptualize the relationship between consumers and brands by establishing the anthropomorphic characteristics of the brand (Sreejesh and Mohapatra 2013). The original development of the concept of a consumer-brand relation returns to Blackstone's (1992) study. It conceptualized consumer-brand relationship as the concept of an association with a brand that includes a complex of cognitive, affective, and behavioral processes, which constitute a relationship between two parties (Sreejesh and Mohapatra, 2013).

There are four conditions to satisfy consumer-brand relationship (Fournier 1998): 1) consumerbrand relationship exists when there is a beneficial exchange between consumers and brands; 2) the interaction between consumers and brands is for a purpose; 3 ) the consumer-brand relationship takes different forms, and 4) the consumer-brand relationship is a process. Based on the four conditions, the consumer-brand relationship is conceptualized as the voluntary or imposed interdependence between a consumer and brand, which characterized by a unique history of interactions and anticipation of future occurrences to facilitate socio-emotional and instrumental goals of the consumers and that involves some types consolidating relations (Sreejesh and Mohapatra 2013).

\subsection{Fan-Brand Relationship In The Sports Industry}

Relationship marketing has attracted considerable attention among marketing practitioners because researchers and sports marketers generally believe that relationship marketing efforts can enhance relationships with sport consumers (Kim et al. 2011). These improved customer relationships can lead to higher team performance results, such as ticket sales, sports media use, and licensed goods sales (Kim et al. 2011). Transposing the close relationship between a consumer and a brand to the dyadic relationship and building a strong tie leads us to the sport context, especially football. In the relationship between consumers and their brands, loyalty is an important element (e.g. Elbedweihy, et al., 2016), but it is a must in football (Cayolla and Loureiro, 2014). Football fans have strong emotions toward their football brands (Cirillo and Cantone, 2015). They always have the passion and motivation to sacrifice for their favorite teams. For example, they have the desire to spend money and time to support their team in a stadium and even fight to attend a match for their favorite club (Cayolla and Loureiro, 2014). Thus, sport managers started to view their teams as the international brand to be managed. The goal of professional sports teams is to build a strong brand, which attracts and affects actual and potential fans, creates opportunities for the extension of the brand merchandising categories and geographic boundaries (Cirillo and Cantone 2015). 


\section{RESEARCH METHODOLOGY}

This study used a mixed research approach in nature where both qualitative and quantitative methods have been deployed. Qualitative research was conducted to gain better insights regarding the consumerbrand relationship in the Egyptian sports industry and to develop the research hypotheses. Then, a quantitative phase has been followed to test these hypotheses. A sequential type of mixed methods was chosen that first preliminary exploratory interviews with Egyptian football fans to gain further insight about their view of the subject area and to develop the research hypothesis. Then, the research subsequently lies primarily in the quantitative approach. The qualitative phase includes a list of questions in line with the interview protocol (Yeong et al. 2018). Football fans were asked in general about the personality of their favorite football teams and how the team's personality may affect their relationship with their teams. The quantitative phase involves gathering and analyzing data for testing hypotheses and using statistical testing.

\subsection{Data Collection Instruments}

We collected data using two instruments. In-depth interviews with target audiences were the first instrument used. Ten interviews were conducted, using the output from these interviews in conjunction with the literature review to gain insight into the topic at hand and develop the research model and hypotheses. A questionnaire was the second instrument in this research to collect the quantitative data. It was a structured, conclusive phase that provides quantitative data for testing the specific hypotheses and examining the relationships between the variables previously outlined. We translated the questionnaire into Arabic for ease of understanding. To reach an equivalent Arabic version of the questionnaire, this English version was subjected to a backward translation process (Brislin, 1986).

\subsection{Measurements}

The scale of Tsiotsou ( 2012) has been used to measure brand personality including five dimensions: competitiveness, prestige, morality, authenticity, and credibility through 24 items in total. Consumer personality has been measured by the scale developed by Mowen (2000). The measurement consists of five dimensions: agreeableness, openness to experiences, introversion, consciousness, and need for arousal. This measurement consists of twenty items (four items for each dimension). Consumer brand relationship has been measured by six dimensions (Fournier 2009). These dimensions are interdependence, commitment, partner quality, self-connection, nostalgic attachment, and intimacy. The scale consists of 30 items.

\subsection{Research Sampling Methods, Types, and Size}

The research population included all fans of Egyptian football teams (premier league and Egypt cup). Egyptian football fans have been chosen as the population of the current study for the following reasons: 1) Fans of football are consumers who have extraordinary behavior with their football brand. Also, football is considered the most popular sport in the world (Cayolla and Loureiro 2014). 2) Consumer-brand relationship (CBR) or fan-team relationship is unique in football. CBR motivates football fans to leave their homes to go to the stadium, travel, and pay a lot of money to watch and support their favorite teams, and even start a quarrel with brothers, sisters, and friends who support different teams. 3) The huge numbers of revenues, brand value, sponsorship of football teams.

The preliminary exploratory interviews were conducted using a judgmental sampling technique, a sample of two football experts and eight football fans were interviewed during that stage. They were selected from various universities and residential areas. For the quantitative phase, a non-probability convenience sample was considered appropriate because the sample frame was not accessible. The focus of the study was on greater Cairo as it incubates people from different backgrounds and different education levels representing the Egyptian culture. The sample size of 471 units was chosen for the study. 


\section{QUALITATIVE DATA ANALYSIS AND RESULTS}

This section first addresses the findings of exploratory research carried out, followed by the research theoretical framework as well as related research hypotheses.

\subsection{Preliminary Interviews And Data Analysis}

Two in-depth personal interviews were conducted with football experts. They have been selected for the interviews because of their experience on the football field and their close contact with football fans. In addition to the personal interviews with experts, eight in-depth interviews were conducted with football fans from different education levels and, different ages (ranging from 19 to 35). The interviewees were selected through a convenient sampling basis. A series of open-ended questions have been used to point out and reveal the different predictors of consumer-brand relationships in the sports industry. Thematic analysis of the interviews illustrated that football experts, as well as all fans, agreed that the personality of a football club affects the relationship between the club and its fans.

\subsubsection{Brand Personality As Fan-Brand Relationship Driver}

Some participants emphasized that the team personality help in forming the relationships between the team and its fans. The following quotes are extracted from the responses of the football fans and experts interviewed, which outline the most significant predictors of the fan-team relationship. For instance, participants showed that the teams must have some characteristics to build strong relationships with their teams such as enthusiasm, following the team-based principles, working hard, having high levels of credibility ....., so on. In other words, the answers support the fact that the personality of a football team (such as credibility, hardworking, braveness, and the team's ability to fulfill its promises) affects the relationship between the football team and its fans.

"My team should be organized, ambitious, enthusiastic, and follow the principles." (Fan 3)

"My team should be hardworking, brave, never surrender, and play to spread joy and happiness." (Fan 5)

"The credibility of my favorite team increases my commitment toward it." (Fan 6)

"The policies of the football team affect the relationship between the football team and its fans." (Expert 1)

"My relationship with my favorite team improves when my team achieves its promised goals and promises.” (Fan 7).

The participants were also asked about their feelings toward their favorite teams and why they have these feelings. The following quotes were extracted from the responses to support that the fanteam relationship is predicted by the personality and behaviors of the football teams toward their fans. For example, when the team takes care of its fans, it enhances the relationships with them. Besides, the teams, which do their best to win in their matches make their fans happy in turn strengthen the relationships with them.

"I adore my team because it takes care of me."(Fan 1)

"I am in love with my team because it wins Fan 7)

"I love my team because it makes me happy." (Fan 2)

"I love my team because it respects its fans." (Fan 6)

The participants were also asked to tell a story or event that shows their attachment to their football teams. The following quotes were extracted from the responses that showing the fans' attachment to 
their football teams. For example, some of fans, particularly who are students, delay their commitments to watch their teams' matches and/or follow their news via different media.

"I used to postpone my assignments to watch my team." (Fan 5)

"When I was at prep school my favorite team was playing in Japan (The FIFA Club World Cup) so I decided not to go to school to watch my team." (Fan 7)

"I cried when my team lost in CAF Champions league." (Fan 2)

\subsubsection{Fan Personality As Fan-Brand Relationship Driver}

The second theme that was emerged from the qualitative data is the fan personality as the diver of building the fan-brand relationship. The participants' answers showed that the consumer-brand relationship in the football industry is unique. They have been asked about their personalities and their relationships with their favorite teams. The following quotes are extracted from the responses to show that the fan-brand relationship is predicted by the fan personality.

"I have the enthusiastic, principles, and do everything to make everyone happy." (Fan 2)

"I share the same ambitious personality." (Fan 1)

"I seek improvement." (Fan 7)

"I never change our principles." (Fan 3)

"My commitment toward my team increases when we share the same personality" (Fan 4)

The participants described some aspects of their personalities, which help in enhancing their relationships with their teams. For example, enthusiasm, having personal principles, making everyone happy, and improving a person's skills are examples of values and personalities that help to build the fan-team relationship or its dimensions such as commitment.

Conclusively, we explored the fan and team personalities, showing their relations with the fanbrand relationship and/or its dimension(s). The following section discusses the research framework and hypotheses to confirm/disconfirm the qualitative results.

\subsection{Research Framework And Hypotheses Development}

Based on the previous research and qualitative findings, the proposed research framework and some research hypotheses were developed. In other words, the research framework was adapted from different studies such as McCrae et al. (1986), Aaker (1997), and Fournier (1998), and supported by the qualitative phase. Figure 1 shows that both brand personality and consumer personality impact each of the consumer-brand relationship dimensions, which include interdependence, commitment, partner quality, self-connection, nostalgic attachment, and intimacy.

\subsubsection{Brand personality and fan-brand relationship dimensions}

Previous research suggested that brand personality positively affects consumer-brand relationships (e.g. Barnes and Pressey 2008; During 2012). Brand interdependence is considered as one of the consumer-brand relationship dimensions (Fournier, 2009). In addition, brand personality affects brand trust, attachment, and commitment positively and directly (Fallahi 2013; Tong et al. 2018). Louis and Lombar (2010) pointed out that the personality traits of the Coca-Cola brand affect brand commitment. Personality positively and significantly affects consumer brand relationship dimensions (Self-Connection, Partner Quality, and Affective Commitment) (Rezaei, Hamidizadeh, and Foroughi 2016). Therefore, we postulate that:

H1: Brand personality has a positive impact on brand interdependence.

$\mathrm{H}$ 2: Brand personality has a positive impact on brand commitment. 
Figure 1. Model of brand and consumer personality affecting eachother

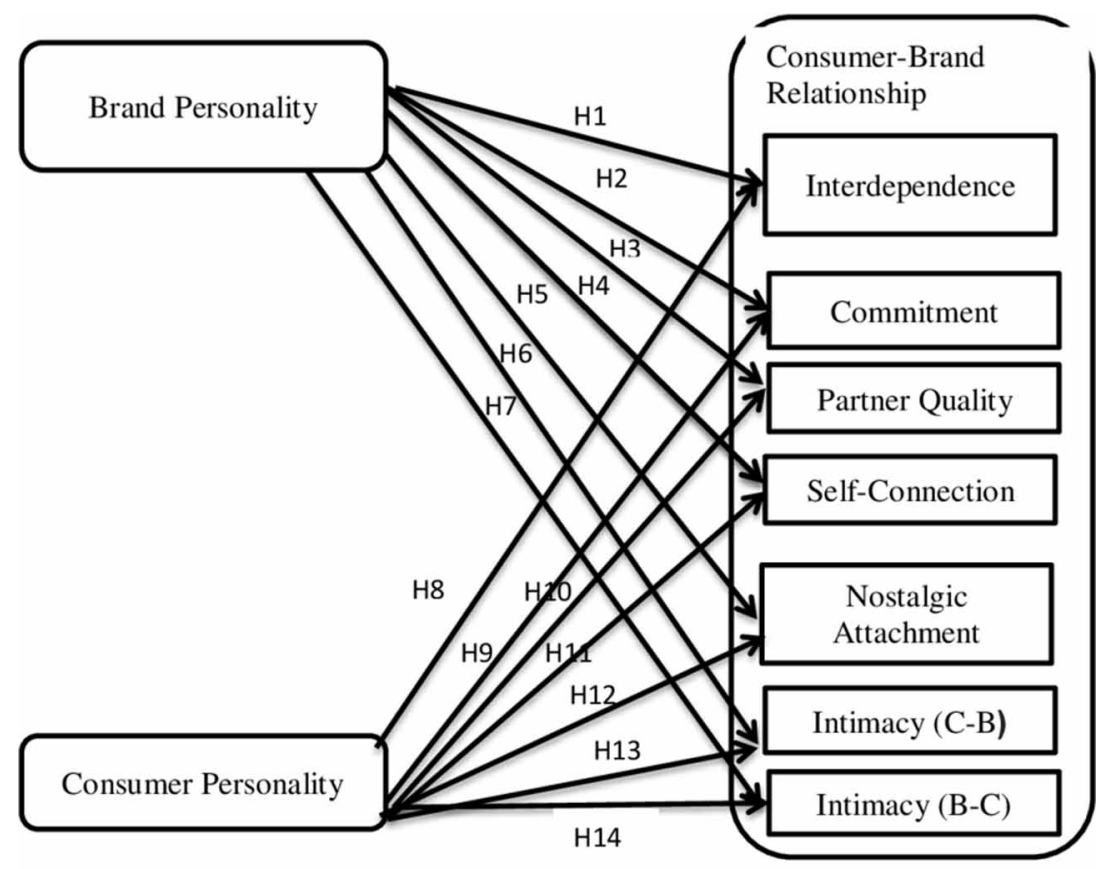

Tho et al. (2016) argued that brand personality appeal positively affects relationship quality and WOM. Respondents perceived brand personality influenced their desirability of the brand as a relationship partner (Bryan et al. 2006). Rezaei et al. (2016) pointed out that personality positively and significantly affects partner quality as one of the consumer-brand relationship dimensions. Besides, Self-connection is related to unique and exited brands (Smit et al, 2007). Paper and Siksha (2017) argued that brand personality directly affects self-connection. Personality positively and significantly affects Self-connection as one of the consumer-brand relationship dimensions. Therefore,

H 3: Brand personality has a positive impact on partner quality.

$\mathrm{H} 4$ : Brand personality has a positive impact on self-connection

Previous studies confirmed the relationships between brand personality and attachment. For example, brand personality influences consumers' attachment (e.g. Fournier, 1998; Parker, 2009; Yao, et al., 2015). Specifically, Paper and Siksha (2017) argued that brand personality directly affected nostalgic attachment. Thus,

H 5: Brand personality has a positive impact on nostalgic attachment.

Proceeding studies showed that brand intimacy represents the consumer-brand relationship (e.g. Wang, and Lee, 2020). Brand intimacy refers to the feeling of closeness derived from a favorable consumer-brand relationship (Almubarak, et al., 2018). It was measured, in some previous studies, based on two dimensions; consumer-brand intimacy, and brand-consumer intimacy. The former dimension refers to the feeling of consumers' closeness to the brand by knowing and understanding the brand well. While the latter dimension refers to the feeling of a brand's closeness to its consumers 
by knowing and understanding them well (e.g. Jana and Das 2017). Brand personality had a positive and direct impact on both dimensions of intimacy (Jana and Das 2017). Thus,

H 6: Brand personality has a positive impact on brand intimacy (fan-brand).

H 7: Brand personality has a positive impact on brand intimacy (brand-fan).

\subsubsection{Fan personality and fan-brand relationship}

The successful consumer-brand relationship depends not only on relationship marketing practices but also on consumer personality (e.g. Ahmad, and Thyagaraj, 2015; Odekerken et al. 2003). In other words, brand interdependence, as a consumer-brand relationship dimension that means the brand plays an important role in consumer's life is normally linked to strong relations between consumers and which suggest how brand-customer relationships should be conceived (Ahmad, and Thyagaraj, 2015). In addition, Rezaei et al. (2016) pointed out that consumer personality positively and significantly affects brand commitment as one of the consumer-brand relationship dimensions. Therefore, we postulate

H8: Fan personality has a positive impact on brand interdependence.

H 9: Fan personality has a positive impact on brand commitment.

The consumer personality positively and significantly affects customer-brand relationship dimensions such as partner quality, and self-connection (e.g. Rezaei et al. 2016). Consumer as a relationship partner plays a critical role build strong relationships (e.g. Papista, and Dimitriadis, 2012). For example, the consumer can evaluate the brand's attitude toward him or her (Ahmad, and Thyagaraj, 2015). Besides, consumers play a vital role in enhancing the relationship with a brand when encreases the self-connection, in which he and the brand share common interests, activities, and opinions (e.g. Ahmad, and Thyagaraj, 2015; Yao, et al., 2015). Thus, we postulate that fan personality positively and significantly affects fan-brand relationship dimensions (self-connection, and partner quality).

H10: Consumer personality has a positive impact on partner quality.

H11: Consumer personality has a positive impact on self-connection.

Preceding research confirmed that consumer personality has a direct effect on brand attachment (e.g. Yao et al. 2015; Mann and Rawat 2016). Therefore, we postulate

H12: Fan personality has a positive impact on nostalgic attachment.

In personality research, the agreeableness traits are most concerned with interpersonal relationships (Graziano et al. 1996). De Raad (2000) argued that consumers with agreeableness traits strive for intimacy. As mentioned that intimacy was measured, in some previous studies, based on two dimensions; consumer-brand intimacy, and brand-consumer intimacy (e.g. Jana and Das 2017), thus,

H 13: Fan personality has a positive impact on brand intimacy (fan-brand).

H 14: Fan personality has a positive impact on brand intimacy (brand-fan). 
Table 1. Descriptive statistics of the sample

\begin{tabular}{|l|l|l|l|l|l|}
\hline Category & Frequency & $\%$ & Category & Frequency & $\%$ \\
\hline \multicolumn{7}{|l|}{ Gender } & 365 & $77.5 \%$ & Favourite Team & \multicolumn{3}{l|}{} \\
\hline Male & 106 & $22.5 \%$ & Zamalek & 370 & $78.6 \%$ \\
\hline Female & 471 & $100 \%$ & Al Masry & 92 & $19.5 \%$ \\
\hline Total & \multicolumn{7}{|l|}{} & Ismaily & 1 & $.2 \%$ \\
\hline Age & 102 & $21.7 \%$ & Wadi Degla & 3 & $.6 \%$ \\
\hline 21 or less & 259 & $55.0 \%$ & Other & 1 & $.2 \%$ \\
\hline 21 to 30 & 84 & $17.8 \%$ & Total & 4 & $.8 \%$ \\
\hline 31 to 40 & 18 & $3.8 \%$ & & 471 & $100 \%$ \\
\hline 41 to 50 & 8 & $1.7 \%$ & & & \\
\hline 51 or more & 471 & $100 \%$ & & & \\
\hline Total & & & & & \\
\hline
\end{tabular}

\section{QUANTITATIVE DATA ANALYSIS AND RESULTS}

\subsection{Descriptive Analysis}

Table 1 presents the sample characteristics for the 471 surveys collected for the study. Of the 471 respondents, $365(77.5 \%)$ were males. The results somehow represent the fact that football is a male sport (McDowell and Schaffner 2011). 55\% of the respondents are between 21 and 30 years old. It's worth noting that almost $79 \%$ of the respondents support Al-Ahly club and $20 \%$ support Al-Zamalek club. The results are somehow close to a study conducted by The Egyptian Centre for Public Opinion Research (Mohamed, 2014). The research found out that $72 \%$ of Egyptian support Al Ahly, while $21 \%$ support $\mathrm{Al} \mathrm{Zamalek.} \mathrm{It} \mathrm{has} \mathrm{been} \mathrm{found} \mathrm{out} \mathrm{that} 53 \%$ of the respondents have a university degree.

\subsection{Inferential Statistics}

Smart PLS has been used to assess the measurement and structural model. Smart PLS is one of the prominent software applications for Partial Least Squares Structural Equation Modelling (Wong, 2013). To evaluate internal consistency, composite reliability and Cronbach's alpha have been examined. Individual indicator reliability and average variance extracted (AVE) have also been examined to evaluate convergent validity. Cross loadings and variable correlation have been examined to evaluate discriminant validity. Table 2 summarizes the reliability test results for the study variables. It's worth noting that the reliability scores for all variables and dimensions are above 0.7 which means that all scales show a satisfactorily level of internal consistency.

Results showed that three items were eliminated. As shown in Table 3, the AVE value for items is above 0.5 with factor loadings above 0.7 (Hair et al., 2017). Discriminant validity ensures that a structural measure is empirically unique and represents phenomena of interest that are not captured by other measures in the structural equation model (Henseler et al. 2015). According to Hair et al. (2017), cross-loadings and the Fornell-Larcker criterion have been estimated to assess the discriminant validity of the measurement model. Table 4 illustrates the cross-loading analysis. The results show that each item loads high on its corresponding dimension which means that the discriminant validity has been confirmed. The Fornell-Larcker criterion is the second discriminant validity assessment approach. In particular, the square root of the AVE of each construct should be greater than its maximum correlation with any other construct ( Hair et al., 2017). Based on the analysis, the square root of AVE in bold for each construct was higher than its total value in the extreme horizontal and 
Table 2. Composite reliability and cronbach's alpha

\begin{tabular}{|c|c|c|c|c|c|}
\hline Variables & \multicolumn{3}{|l|}{ Composite Reliability } & \multicolumn{2}{|c|}{ Cronbach's Alpha } \\
\hline Brand personality & \multicolumn{3}{|l|}{0.964} & \multicolumn{2}{|l|}{0.961} \\
\hline Consumer personality & \multicolumn{3}{|l|}{0.864} & \multicolumn{2}{|l|}{0.840} \\
\hline \multirow[t]{7}{*}{ Consumer brand relationship } & Interdependence & 0.897 & \multirow[t]{7}{*}{0.968} & 0.828 & \multirow[t]{7}{*}{0.965} \\
\hline & Commitment & 0.912 & & 0.883 & \\
\hline & Partner Quality & 0.931 & & 0.906 & \\
\hline & Self-connection & 0.936 & & 0.918 & \\
\hline & Nostalgic attachment & 0.911 & & 0.853 & \\
\hline & Intimacy (fan-brand) & 0.931 & & 0.889 & \\
\hline & Intimacy (brand-fan) & 0.904 & & 0.841 & \\
\hline
\end{tabular}

vertical column. Values in bold represent the AVE's square root and the non-bold values represent the inter-correlation between the constructs. The square root of the AVE of each construct was greater than its maximum correlation with any other construct. Consequently, the discriminant criteria of Fornell and Larcker validity were met.

\subsection{Assessment Of Structural Model}

After confirming the reliability and validity of the measurement model, the following step is to assess the structural model results.

\subsubsection{Testing for Multicollinearity, Coefficient of Determination (R2), and Effect Size $\left(F^{2}\right)$}

The assumption of no multicollinearity between the independent variables is supported with VIF values far below 10 and tolerance values of more than 0.1 . The results showed that the $\mathrm{R}^{2}$ of all the endogenous latent variables of the study are equal and greater than 0.10 . The values of the effect size of brand personality on the dependent variables were between 0.02 and 0.15 which indicates a small effect size, except for nostalgic attachment (0.019) which is considered as no effect size. According to consumer personality, the values of effect size are between 0.02 and 0.15 .

\subsubsection{Predictive Relevance $\left(Q^{2}\right)$ and Goodness of Fit (GoF)}

The results showed that all $\mathrm{Q}^{2}$ values are above zero which means that the model has predictive relevance. According to Tenenhaus et al. (2005), the goodness of fit can be defined as the global fit measure. It is geometric of AVE and the average of $\mathrm{R}^{2}$ of the endogenous variables. Regarding the research model, the GoF value is 0.30 which is between 0.25 and 0.36 . It means that the GoF of the research model is medium.

\section{HYPOTHESES TESTING AND DISCUSSION OF RESULTS}

Table 5 shows the results of hypothesis testing. Results of the analysis showed that brand personality has a strong positive impact on interdependence $(\beta=0.216, \mathrm{p}<0.001)$, supporting H1. The results also showed that brand personality has a strong positive impact on brand commitment $(\beta=0.191$, $\mathrm{p}=0.001$ ), supporting $\mathrm{H} 2$. This result is following what was presented in the literature by previous research (e.g. Fallahi, 2013; Tong et al. 2018).

The results showed that brand personality has a strong positive impact on partner quality $(\beta$ $=0.260, \mathrm{p}<0.001$ ), supporting H3. This result is following what was presented in the literature (e.g. 
Table 3. Convergent validity statistics

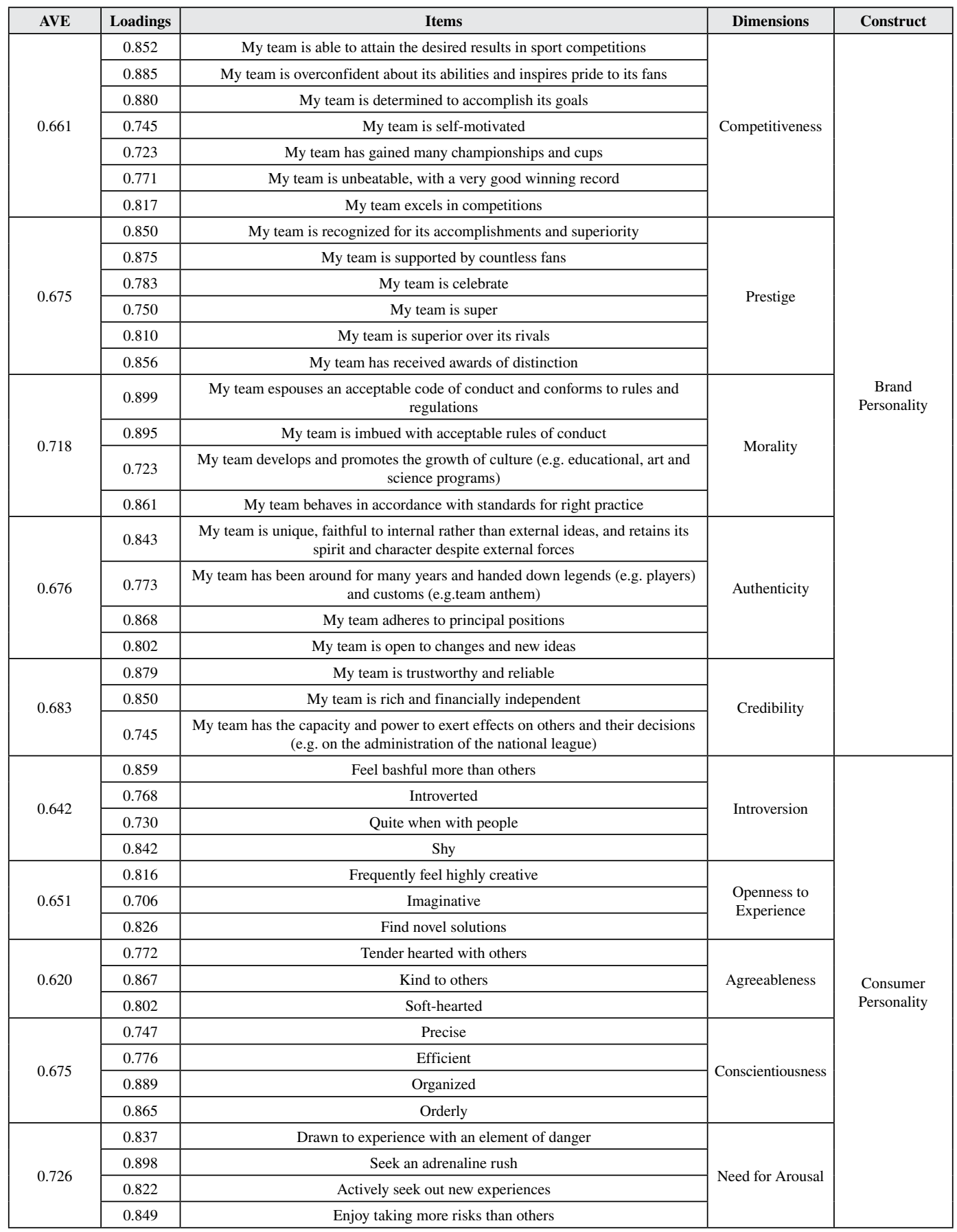


Table 3. Continued

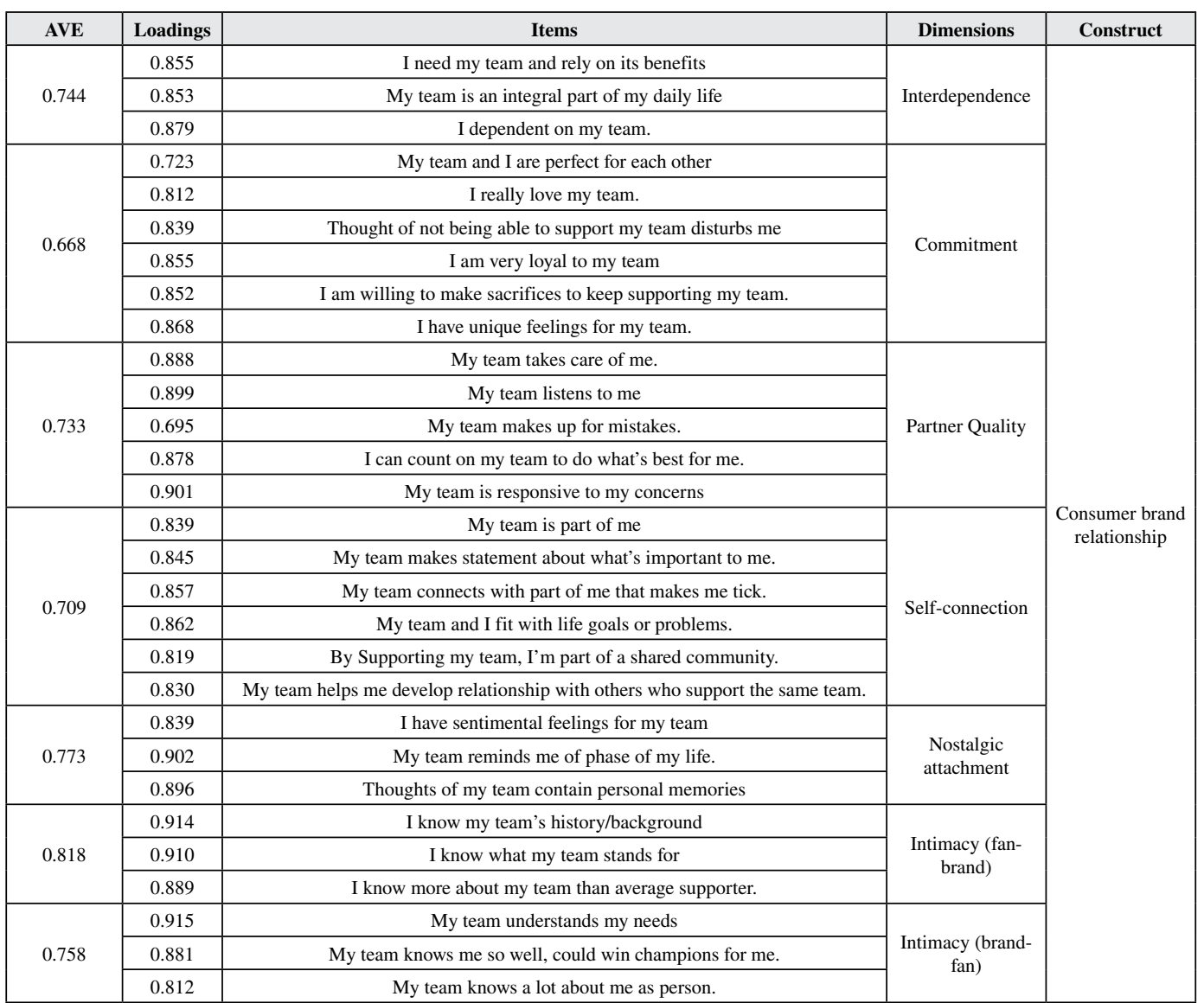

Bryan Hayes et al., 2006; Tho et al. 2016). Results of the analysis of the collected sample showed that brand personality has a strong positive impact on self-connection $(\beta=0.208, p<0.001)$, supporting H4. This result is following what was presented in the literature by Smit et al. (2007). The results also showed that brand personality has a strong positive impact on nostalgic attachment $(\beta=0.139$, $\mathrm{p}<0.05$ ), supporting H5. This result is following what was presented in the literature (e.g. Paper and Siksha 2017). The results showed that brand personality has a strong positive impact on intimacy (fan-brand) $(\beta=0.163, \mathrm{p}<0.05)$, supporting H6. This result is following what was presented in the literature by (e.g. Jana and Das 2017). The results also showed that brand personality has a strong positive impact on intimacy (brand-fan) $(\beta=0.227, \mathrm{p}<0.001)$, supporting H7. This result supports what was presented in the literature by (e.g. Jana and Das 2017).

The results showed that consumer personality has a strong positive impact on interdependence $(\beta=0.241, \mathrm{p}<0.001)$, supporting H8. This result is following what was presented in the literature by(e.g. Odekerken, et al., 2003). The results also showed that consumer personality has a strong positive impact on brand commitment $(\beta=0.316, \mathrm{p}<0.001)$, supporting H9. This result is following what was presented in the literature (e.g. Srivastava and Owens 2010). The results showed that consumer personality has a strong positive impact on partner quality $(\beta=0.172, \mathrm{p}<0.001)$, supporting H10. This result is following what was presented in the literature (e.g. Rezaei et al. 2016). The results also showed that 


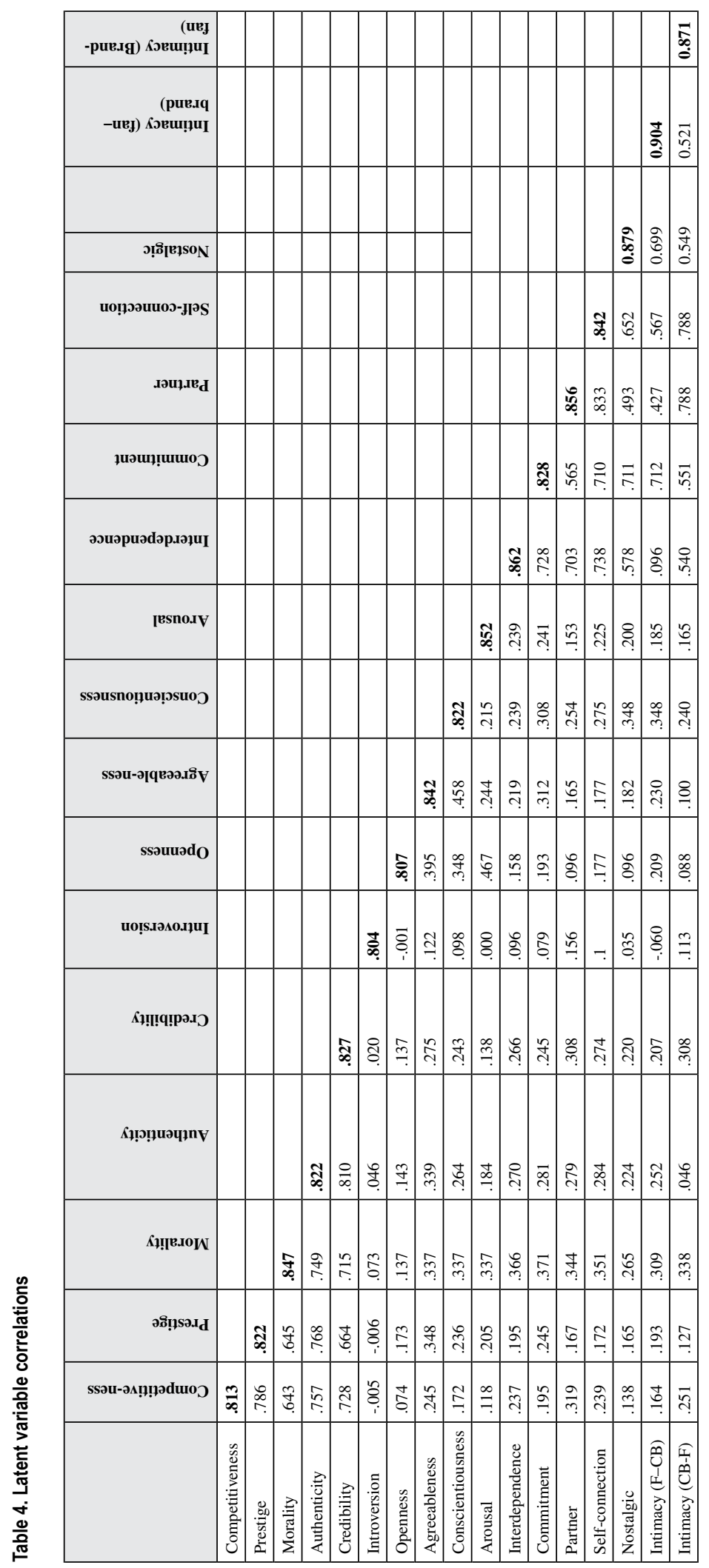


Table 5. Path coefficient of the research hypotheses

\begin{tabular}{|c|c|c|c|c|c|}
\hline Hypothesis & Relationship & Std. Beta & T- Value & P- value & Decision \\
\hline H1 & Brand Personality $>$ Interdependence & 0.216 & 4.412 & 0.000 & Supported $* *$ \\
\hline $\mathrm{H} 2$ & Brand Personality $>$ Commitment & 0.191 & 3.410 & 0.001 & Supported $* *$ \\
\hline $\mathrm{H} 3$ & Brand Personality $>$ Partner quality & 0.260 & 4.350 & 0.000 & Supported $* *$ \\
\hline $\mathrm{H} 4$ & Brand Personality $>$ Self-connection & 0.208 & 3.652 & 0.000 & Supported $* *$ \\
\hline H5 & Brand Personality $>$ Nostalgic & 0.139 & 2.528 & 0.012 & Supported $*$ \\
\hline H6 & Brand Personality $>$ Intimacy $(\mathrm{C}-\mathrm{B})$ & 0.163 & 2.850 & 0.005 & Supported $* *$ \\
\hline $\mathrm{H} 7$ & Brand Personality > Intimacy $(\mathrm{B}-\mathrm{C})$ & 0.227 & 3.654 & 0.000 & Supported $* *$ \\
\hline $\mathrm{H} 8$ & Consumer Personality $>$ Interdependence & 0.241 & 5.487 & 0.000 & Supported $* *$ \\
\hline H9 & Consumer Personality $>$ Commitment & 0.316 & 7.797 & 0.000 & Supported $* *$ \\
\hline H10 & Consumer Personality $>$ Partner quality & 0.172 & 3.796 & 0.000 & Supported $* *$ \\
\hline H11 & Consumer Personality $>$ Self-connection & 0.250 & 5.659 & 0.000 & Supported** \\
\hline $\mathrm{H} 12$ & Consumer Personality $>$ Nostalgic & 0.242 & 5.469 & 0.000 & Supported $* *$ \\
\hline $\mathrm{H} 13$ & Consumer Personality $>$ Intimacy $(\mathrm{C}-\mathrm{B})$ & 0.254 & 5.709 & 0.000 & Supported $* *$ \\
\hline H14 & Consumer Personality > Intimacy $(B-C)$ & 0.155 & 3.163 & 0.002 & Supported $* *$ \\
\hline
\end{tabular}

* Significant at $p<0.05$ ** Significant at $p<0.001$

consumer personality has a strong positive impact on self-connection $(\beta=0.250, \mathrm{p}<0.001)$, supporting H11. This result supports what was presented in the literature (e.g. Ye et al. 2015).

The results showed that consumer personality has a strong positive impact on nostalgic attachment $(\beta=0.242, \mathrm{p}<0.001)$, supporting H12. The results showed that consumer personality has a strong positive impact on intimacy (fan-brand) $(\beta=0.254, \mathrm{p}<0.001)$, supporting H13. This result is following what was presented in the literature (e.g. Myers et al. 2010). Finally, the results showed that consumer personality has a strong positive impact on Intimacy (brand-brand) $(\beta=0.155, \mathrm{p}<0.001)$, supporting H14. This result is following what was presented in the literature by (e.g. Myers et al. 2010).

\section{THEORETICAL IMPLICATIONS}

This study provides insights into the consumer-brand relationships to decrease the lack of knowledge in the sport brand relationships context (e.g. Kunkel and Biscaia 2020). It also supports using of brand personality and consumer personality in developing the consumer-brand relationship in the sports industry (i.e. football field). The use of consumer-brand relationship theory (Fournier 1998) is effective in the explanation of the relationships between football teams and their fans. This theory was developed based on the idea that consumers humanize objects and think of brands as if they have human personalities. Brands cannot act, feel or think themselves, but can live and evolve through the practices of their managers (Loureiro 2013). Football teams, which have a well-established brand personality, have a strong relationship with their fans. It also illustrates that the personality of football fans has a positive impact on the shaping and developing process of fan-team relationships. The study contributes to services marketing literature by providing an overarching model that presents significant antecedents to consumer-brand relationships in the sports industry. 


\section{MANAGERIAL IMPLICATIONS}

The personality of the football team seems to have a strong impact on the relationship between football teams and their fans, resulting in fans spending more time and retail on the team and their related products. Teams should work to enhance the competitiveness, prestige, morality, authenticity, and credibility of the team. Based on the results of the current study, focusing some marketing efforts on communicating the unique facets of the personality of the team may be beneficial. To improve the perception of the competitiveness of the team, the football team should promote the success of the team and its players, the championship, the cups, and the rewards the team has gained. The football team should hire well-experienced football managers and acquire high-performance football players to enhance their competitiveness leading to a better personality of the team. The results of the study suggest that the prestige of the football team may be enhanced through communicating the team's accomplishments and superiority. For instance, advertisements that promote the team include images for the team and its players celebrating their awards, best matches, and best records.

To enhance the perception of the morality of the team, the football team should behave following standards for right practice; have a code of conduct, and respect regulations. The team should also develop and promote the growth of culture (e.g. educational, art, science programs). Football teams, for example, can launch a publicity campaign to encourage and call for compliance with regulations and right practices. In other words, promoting the team's involvement and supporting educational, art, and science programs via different advertising tools. The study results suggest that the team's authenticity can be improved by conveying the uniqueness, originality, and legendary features of the team. For example, the unique records of the team in different championships and the team's oldness compared to other competitors can be promoted. To enhance the perception of the team's credibility, the football team should behave following standards and pay great attention to their promises, and do their best to fulfill these promises to increase their trustworthiness and reliability.

\section{LIMITATIONS AND FUTURE RESEARCH FRONTIERS}

Although the research has provided some insights, some research limitations need to be addressed. The cross-sectional research design sets limitations on the generalization of the current study findings. Future research might address this issue with the adoption of a longitudinal research design to emphasize and illustrate the causality in the hypothesized relationships of the study. The study has been conducted in only one sports industry (Football only). Accordingly, the results cannot be generalized to other service settings. Future research needs to re-test the proposed conceptual framework in other service contexts (e.g. health clubs, telecommunication, education) to compare the results of both service contexts. Because it was very difficult to obtain a sampling frame, the research relied on a non-probability judgmental sample that considered distributing the questionnaires in only limited places in Greater Cairo. Accordingly, generalization is to be made with great caution. Further research could apply the current research model to a more representative sample for more validation. 


\section{REFERENCES}

Aaker, J. (1997). Dimensions of brand personality. JMR, Journal of Marketing Research, 34(3), 347-356. doi:10.1177/002224379703400304

Aaker, J., \& Fournier, S. (1995). A Brand as a Character, a Partner and a Person: Three Perspectives on the Question of Brand Personality. Advances in Consumer Research. Association for Consumer Research (U. S.), $22,391-395$.

Ahmad, A., \& Thyagaraj, K. (2014). Applicability of brand personality dimensions across cultures and product categories: A review. Global Journal of Finance and Management, 6(1), 9-18.

Ahmad, A., \& Thyagaraj, K. (2015). 'Understanding the Influence of Brand Personality on Consumer Behavior. Journal of Advanced Management Science, 3(1), 38-43. doi:10.12720/joams.3.1.38-43

Almubarak, A., Pervan, S., \& Johnson, L. (2018). A conceptual analysis of brand intimacy on social media platforms. Journal of Strategic Marketing, 26(6), 463-478.

Asadollahi, A., Heidarzadeh, H., Abdolvand, M., \& Reshadatjooh, H. (2015). Developing a Scale Sports Brand Personality in Iranian Sports Teams. Research Journal of Recent Sciences, 4(11), 83-87.

Azoulay, A., \& Kapferer, J. (2003). Do brand personality scales really measure brand personality? Journal of Brand Management, 11(2), 143-155. doi:10.1057/palgrave.bm.2540162

Barnes, S., \& Pressey, A. (2008). An examination of market maven behavior across real-life, web and virtual world marketing channels: in search of the meta maven'? Academic Press.

Blank, A., Koenigstorfer, J., \& Baumgartner, H. (2018). Sports team personality: It's not all about winning! Sport Management Review, 21(2), 114-132. doi:10.1016/j.smr.2017.05.004

Bosnjak, M., Bochmann, V., \& Hufschmidt, T. (2007). Dimensions of brand personality attributions: A personcentric approach in the German cultural context. Social Behavior and Personality, 35(3), 303-316. doi:10.2224/ sbp.2007.35.3.303

Bray, J. (2008). Consumer behavior theory: Approaches and models. Academic Press.

Brislin, R. (1986). The wording and translation of research instruments. Academic Press.

Bryan, H., Alford, B., Silver, L., \& York, R. (2006). Looks matter in developing consumer-brand relationships. Journal of Product and Brand Management, 15(5), 306-315. doi:10.1108/10610420610685875

Cayolla, R., \& Loureiro, S. (2014). Fans club brand relationship: football passion. International Journal of Business and Globalisation, 12(1), 82-97.

Chang, P., \& Chieng, M. (2006). Building consumer-brand relationship: A cross-cultural experiential view. Psychology and Marketing, 23(11), 927-959. doi:10.1002/mar.20140

Cirillo \& Cantone. (2015). Consumer-brand relationship. The case of football fandom. In Proceedings International Marketing Trends Conference. Napoli: Università Federico II.

De Raad, B. (2000). The Big Five Personality Factors: The psychological approach to personality. Hogrefe and Huber Publishers.

Deloitte. (2008). Potential Economic Impact of the Rugby World Cup on a Host Nation. Author.

During, S. (2012). The effect of positivity of the blog on brand attitude and purchase intention: An empirical blog study. Erasmus University.

Elbedweihy, A., Jayawardhena, C., Elsharnouby, M., \& Elsharnouby, T. (2016). Customer relationship building: The role of brand attractiveness and consumer-brand identification. Journal of Business Research, 69(8), 2901-2910. doi:10.1016/j.jbusres.2015.12.059

Elsharnouby, M., Mohsen, J., Saeed, O., \& Mahrous, A. (2021). Enhancing resilience to negative information in consumer-brand interaction: The mediating role of brand knowledge and involvement. Journal of Research in Interactive Marketing. Advance online publication. doi:10.1108/JRIM-05-2020-0107 
Fajer, M., \& Schouten, J. (1995). Breakdown and dissolution of person-brand relationships. ACR North American Advances.

Fallahi, M. (2013). A Study of the Effects of Brand Personality on Three Constructs : Brand Trust, Brand Attachment, and Brand Commitment in Imam Khomeini Port City. Interdisciplinary Journal of Contemporary Research in Business, 5(8), 156-170.

Fetscherin, M., \& Heinrich, D. (2015). Consumer brand relationships research: A bibliometric citation metaanalysis. Journal of Business Research, 68(2), 380-390. doi:10.1016/j.jbusres.2014.06.010

Field, A. (2009). Discovering Statistics Using SPSS (3rd ed.).

Fournier, S. (1998). Consumers and their brands: Developing relationship theory in consumer research. The Journal of Consumer Research, 24(4), 343-373. doi:10.1086/209515

Fournier, S. (2009). Lessons Learned About Consumers' Relationships with Their Brands. Handbook of Brand Relationships, 2670, 5-23.

Geuens, M., Weijters, B., \& De Wulf, K. (2009). A new measure of brand personality. International Journal of Research in Marketing, 26(2), 97-107. doi:10.1016/j.jiresmar.2008.12.002

Ghantous, N. (2016). The impact of services brand personality on consumer-brand relationship quality. Services Marketing Quarterly, 37(3), 185-199. doi:10.1080/15332969.2016.1184544

Goldman, M., \& Johns, K. (2009). Sportainment: Changing the pace of limited-overs cricket in South Africa. Management Decision, 47(1), 124-136. doi:10.1108/00251740910929740

Gordon, W. (1996). Accessing the Brand Through Research. In D. Cowley (Ed.), Understanding Brands. Kogan Page.

Graziano, W., Jensen-Campbell, L., \& Hair, E. (1996). Perceiving interpersonal conflict and reacting to it: The case for agreeableness. Journal of Personality and Social Psychology, 70(4), 820-835. doi:10.1037/00223514.70.4.820 PMID:8636901

Guèvremont, A., \& Grohmann, B. (2013). The impact of brand personality on consumer responses to persuasion attempts. Journal of Brand Management, 20(6), 518-530. doi:10.1057/bm.2012.58

Hair, J. Jr, Hult, G., Ringle, C., \& Sarstedt, M. (2017). A primer on partial least squares structural equation modeling (PLS-SEM). Sage Publications.

Hartman, K., \& Spiro, R. L. (2005). Recapturing store image in customer-based store equity: A construct conceptualization. Journal of Business Research, 58(8), 1112-1120. doi:10.1016/j.jbusres.2004.01.008

Henseler, J., Ringle, C., \& Sarstedt, M. (2015). A new criterion for assessing discriminant validity in variancebased structural equation modeling. Journal of the Academy of Marketing Science, 43(1), 115-135. doi:10.1007/ s11747-014-0403-8

IEG. (2018). What Sponsors Want and Where Dollars Will Go in 2018. IEG.

Jana, S., \& Das, J. (2017). How Intimate are You with Your Preferred Brand?-A Study on Brand Personality Congruence. Pertanika Journal of Social SciencesandHumanities, 25(2).

Kapferer, J. (1997). Strategic Brand Management: Creating and Sustaining Brand Equity Long Term. Kogan Page.

Karjaluoto, H., Munnukka, J., \& Salmi, M. (2016). How do brand personality, identification, and relationship length drive loyalty in sports? Journal of Service Theory and Practice, 26(1), 50-71. doi:10.1108/JSTP-092014-0206

Keller, K. (2001). Building customer-based brand equity: A blueprint for creating strong brands. Marketing Science Institute.

Kessous, A., Roux, E., \& Chandon, J. (2015). Consumer-brand relationships: A contrast of nostalgic and nonnostalgic brands. Psychology and Marketing, 32(2), 187-202. doi:10.1002/mar.20772 
Kim, Y., Kim, S., Lee, S., \& Cho, S. (2019). A structural validation of brand personality scale: Assessing the congruence effects of sport sponsorship. Measurement in Physical Education and Exercise Science, 23(4), 351-363. doi:10.1080/1091367X.2018.1523794

Kim, Y., Trail, G., \& Ko, Y. (2011). The influence of relationship quality on sport consumption behaviors: An empirical examination of the relationship quality framework. Journal of Sport Management, 25(6), 576-592. doi:10.1123/jsm.25.6.576

Kunkel, T., \& Biscaia, R. (2020). Sports brands: Brand relationships and consumer behavior. Sport Marketing Quarterly, 29(1), 3-17. doi:10.32731/SMQ.291.032020.01

Lee, H., \& Cho, C. (2009). The matching effect of brand and sporting event personality: Sponsorship implications. Journal of Sport Management, 23(1), 41-64. doi:10.1123/jsm.23.1.41

Louis, D., \& Lombart, C. (2010). Impact of brand personality on three major relational consequences (trust, attachment, and commitment to the brand). Journal of Product and Brand Management, 19(2), 114-130. doi:10.1108/10610421011033467

Loureiro, S. (2013). Consumer-brand relationship: Foundation and state-of-the-art. In Customer-centric marketing strategies: Tools for building organizational performance (pp. 414-434). IGI Global. doi:10.4018/978-1-46662524-2.ch020

Mann, B., \& Rawat, J. (2016). The role of consumer personality trait and brand personality trait in creating customer experience. IUP Journal of Brand Management, 13(3), 23.

Mayer, J. (2007). Asserting the definition of personality. The Online Newsletter for Personality Science, 1, 1-4.

McCrae, R., \& Costa, P. Jr. (1986). Personality, coping, and coping effectiveness in an adult sample. Journal of Personality, 54(2), 385-404. doi:10.1111/j.1467-6494.1986.tb00401.x

McDowell, J., \& Schaffner, S. (2011). Football, it's a man's game: Insult and gendered discourse in The Gender Bowl. Discourse \& Society, 22(5), 547-564. doi:10.1177/0957926511405574

Mitsis, A., \& Leckie, C. (2016). Validating and extending the sports brand personality scale. Journal of Service Theory and Practice, 26(2), 203-221. doi:10.1108/JSTP-08-2014-0185

Mohamed, H. (2014). "Basira" Center announces: 72\% of Egyptians are "Ahlawi", 21\% are fans of Zamalek, and the older categories are more encouraging for the White Club. 19\% of citizens saw the final of the

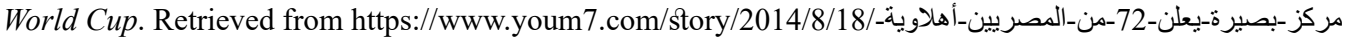
و و1825070/21 و

Myers, S., Sen, S., \& Alexandrov, A. (2010). The moderating effect of personality traits on attitudes toward advertisements: a contingency framework. Management and Marketing, 5(3).

Paper, C., \& Siksha, A. (2017). Do brand personality congruence lead to consumer-brand relationships? Extended Abstract.

Papista, E., \& Dimitriadis, S. (2012). Exploring consumer-brand relationship quality and identification. Qualitative Market Research, 15(1), 33-56. doi:10.1108/13522751211191982

Parker, B. (2009). A comparison of brand personality and brand user-imagery congruence. Journal of Consumer Marketing, 26(3), 175-184. doi:10.1108/07363760910954118

Ratten, V., \& Ratten, H. (2011). International sport marketing: Practical and future research implications. Journal of Business and Industrial Marketing, 26(8), 614-620. doi:10.1108/08858621111179886

Rezaei, M., Hamidizadeh, M., \& Foroughi, F. (2016). Explain and evaluate the congruence between the brand personality and word of mouth advertising. Bulletin de la Société Royale des Sciences de Liège, 85, 1514-1528.

Schade, M., Piehler, R., \& Burmann, C. (2014). Sports club brand personality scale (SCBPS): A new brand personality scale for sports clubs. Journal of Brand Management, 21(7-8), 650-663. doi:10.1057/bm.2014.36

Seimiene, E. (2012). Emotional connection of consumer personality traits with brand personality traits: Theoretical considerations. Economics and Management, 17(4), 1472-1478. doi:10.5755/j01.em.17.4.3016 
Smit, E., Bronner, F., \& Tolboom, M. (2007). Brand relationship quality and its value for personal contact. Journal of Business Research, 60(6), 627-633. doi:10.1016/j.jbusres.2006.06.012

Solomon, M. (2011). Consumer behavior: buying, having, and being ( $9^{\text {th }}$ ed.). Pearson.

Sreejesh, S., \& Mohapatra, S. (2013). Mixed Method Research Design: An Application in Consumer-Brand Relationships $(C B R)$. Springer Science and Business Media.

Srivastava, P., \& Owens, D. (2010). Personality traits and their effect on brand commitment: An empirical investigation. Marketing Management Journal, 20(2), 15-27.

$\mathrm{Su}$, Y. (2009). Exploring the concepts and practices of relationship marketing within Taiwanese banks (Doctoral dissertation). Bournemouth University.

Tenenhaus, M., Vinzi, V., Chatelin, Y., \& Lauro, C. (2005). PLS path modelling. Computational Statistics \& Data Analysis, 48(1), 159-205. doi:10.1016/j.csda.2004.03.005

Tho, N., Trang, N., \& Olsen, S. (2016). Brand personality appeal, brand relationship quality, and WOM transmission: A study of consumer markets in Vietnam. Asia Pacific Business Review, 22(2), 307-324. doi:10 $.1080 / 13602381.2015 .1076655$

Tong, X., Su, J., \& Xu, Y. (2018). Brand personality and its impact on brand trust and brand commitment: An empirical study of luxury fashion brands. International Journal of Fashion Design, Technology, and Education, 11(2), 196-209. doi:10.1080/17543266.2017.1378732

Tsiotsou, R. (2012). Developing a scale for measuring the personality of sports teams. Journal of Services Marketing, 26(4), 238-252. doi:10.1108/08876041211237541

Udo-Imeh, P., Festus, N., Eyo, A., \& Essien, E. (2015). Personality and Consumer Behaviour: A Review. European Journal of Business and ManagementOnline, 7(18).

Wang, T., \& Lee, F. (2020). Examining customer engagement and brand intimacy in social media context. Journal of Retailing and Consumer Services, 54, 102035. doi:10.1016/j.jretconser.2020.102035

Wong, K. (2013). Partial least squares structural equation modeling (PLS-SEM) techniques using SmartPLS. Marketing Bulletin, 24(1), 1-32.

Yao, Q., Chen, R., \& Xu, X. (2015). Consistency between consumer personality and brand personality influences brand attachment. Social Behavior and Personality, 43(9), 1419-1427. doi:10.2224/sbp.2015.43.9.1419

Yeong, M., Ismail, R., Ismail, N., \& Hamzah, M. (2018). Interview protocol refinement: Fine-tuning qualitative research interview questions for multi-racial populations in Malaysia. Qualitative Report, 23(11), 2700-2713.

Yoon, T. (2004).An empirical study of the concept of brand personality: The case of restaurants(Doctoral dissertation). University of Surrey.

Zamalek SC - Club Profile I Transfermarkt. (n.d.). Retrieved January 11, (2019), from https://www.transfermarkt. com/zamalek-sc/startseite/verein/664/saison_id/2018

Mohamed H. Elsharnouby is an assistant professor of marketing in the Business Administration Department at Badr University in Cairo (BUC), and is currently on leave from the Cairo University, where he is a tenured Faculty Member. He received his Ph.D. from Hull University Business School, United Kingdom. Current research interests include relationship new technology in marketing, advertising, and relationship marketing. His work appeared in a number of journals and proceedings, including Journal of Business Research, Journal of research in interactive marketing, Academy of Marketing Science, American Marketing Association Conference, European Marketing Academy Conference, and Academy of Marketing Conference. 